\title{
Os 7 princípios de atualização: diretrizes de contextualização do texto bíblico
}

\author{
The 7 principles of update: \\ guidelines of contextualization of the biblical text
}

Vitor de Oliveira Abreu

\section{Resumo}

Este artigo ao passo que recapitula algumas diretrizes hermenêuticas, na realidade, pretende também por em debate o papel da ciência bíblica em veicular a mensagem profunda e viva do texto bíblico de modo objetivo e explícito para o contexto hodierno, encarando tal procedimento de atualização como uma tarefa pertinente também ao exercício exegético que, mais do que apenas investigar o passado, também objetiva uma leitura atualizada e revigorante capaz de contribuir na transformação salutar dos fatos concretos do presente.

Palavras-chave: história-salvífica; método-exegético; significado essencial; contextualização.

\begin{abstract}
This article while recapitulates some hermeneutical guidelines, in fact, also intends to put into discussion the role of biblical science in relaying the profound message and living the biblical text in an way objective and explicit to hodiernal context, facing such update procedure as a relevant task also to exegetical exercise, that more than just investigating the past, also objective a refreshed and invigorating reading able to contribute to the healthy transformation of the facts of the present.
\end{abstract}

Keywords: history-saving; exegetical method; essential meaning; contextualization. 


\section{Introdução}

Todo método de interpretação tem limite. Talvez tenha sido esta a razão pela qual Rafael Aguirre nos trouxe uma plural e brilhante contribuição quando reuniu e organizou a análise dos mesmos textos bíblicos sob diferentes perspectivas metodológicas: pelos métodos histórico-críticos, depois pela análise narrativa, também pela perspectiva antropológica cultural, etc. Este empreendimento demonstrou a importância dialética entre métodos distintos com uma finalidade de complementaridade em direção a uma tentativa de compreensão mais completa sobre o objeto de estudo, descobrindo sua profunda intenção significativa, cada um ao seu modo, sem necessidade de transformar o palco de estudos dos textos, como ele mesmo disse, "em campo de batalha de preconceitos ideológicos" . De semelhante natureza, mas de outro modo, o documento "A Interpretação da Bíblia na Igreja"² põe em relevo a necessidade de complementações quando apresenta vários métodos interpretativos e as várias abordagens em suas propostas e limitações.

$\mathrm{O}$ próprio conjunto de métodos histórico-críticos (doravante $\mathrm{MHC}$ ) demonstra a importância de interação complementar dos passos metódicos e que, apesar da hegemônica posição acadêmica, este conjunto sempre estará no caminho de aperfeiçoamentos. Por muito tempo foi considerado apenas como uma ferramenta diacrônica, desde os meados do séc. XIX tem sido usado para dissecar e "recortar" as "glosas" e "acréscimos" a fim de descobrir um texto "origem", e para muitos da época somente este texto "origem" ou "fonte" seria o "legítimo". Alguns chegaram cogitar que esta parte do texto seria a única dotada de inspiração divina e para outros até mesmo inexistiria tal inspiração. Contudo, hoje não se lida com o método deste modo para validar parte "a" ou "b" do texto, além do fato de que não está no nível de nenhuma técnica mensurar a inspiração divina de um texto. Aliás, nenhum método literário pretende e nem mesmo tem condições de tratar o mérito de tal postulação, não é seu objetivo, competência ou finalidade, seu campo perscrutíneo é outro. Entretanto, a fim de evitar o erro ocorrido no passado, hoje é imprescindível que no uso do MHC, por um lado, se chegue a uma síntese no final da exegese e, por outro, interroguemos sobre a contextualização funcional desta sintese final. É exatamente neste ponto que se situa a contribuição deste artigo.

\footnotetext{
${ }^{1}$ AGUIRRE, R. Os milagres de Jesus: perspectivas metodológicas plurais. São Paulo: Edições Loyola, 2009, p. 7.

2 PONTIFÍCIA COMISSÃO BÍBLICA. A interpretação da Bíblia na Igreja. São Paulo: Paulinas, 1994.
} 
Resumindo, o ponto de partida da análise do MHC é o texto em sua forma sincrônica, o desdobrar será diacrônico, mas a síntese final ou conclusão levará a compreender o texto na totalidade de seu conjunto sincrônico ${ }^{3}$ (se heterogênio, podemos dizer "na reunião das várias camadas" ou "na reunião dos conteúdos" de sentido) na unidade literária tal como a conhecemos hoje. Em outras palavras, o MHC permite a união destas duas perspectivas (sincrônica e diacrônica) na persecução do significado do texto, em sua literalidade e na ampliação da compreensão deste significado "através" do tempo (evolução textual). Porém, isto nos leva à validade da seguinte pergunta: até que ponto esta sintese final consegue ecoar um significado de voz audível para as experiências de vida e questões vitais do leitor atual? Ou se realmente este exercício exegético se trata mais de um "passatempo elegante, que nem prejudica e nem ajuda"? ${ }^{4}$ Então, a pergunta vital seria: quando chegar ao seu termo qual será a relevância funcional desta síntese final ao leitor de hoje?

Devido à falta de adesão destas duas perspectivas e pelo uso de cunho marcadamente cético a que o MHC foi submetido, muito do resultado obtido gerou conclusões de que se trata de uma "exegese árida e estéril" para a Igreja e para o ouvinte hodierno. Nisto cresceram múltiplas acusações (até muito agressivas) quanto à falta de diálogo da ciência bíblica, com as necessidades eclesiais vigentes 5 . Porém, na realidade, não tem que ser assim. Do contrário, a maioria dos manuais de exegese não reservariam capítulos ou seções sobre o procedimento hermenêutico de atualização, como podemos ver que geralmente fazem ${ }^{6}$. Além do mais, por exemplo, a própria interpretabilidade diacrônica permite perseguir o significado profundo de temas no conjunto de textos das Sagradas Escrituras, cujos temas se constituem em fios-condutores da revelação progressiva, em que "progressiva" mesmo não é em si a manifestação divina na História, e sim a compreensão do sentido que

\footnotetext{
${ }^{3}$ OTTO, E. A Lei de Moisés. São Paulo: Ed. Loyola, 2011, p. 13.

${ }^{4}$ SIMIAN-YOFRE, H. (coord.). Metodologia do Antigo Testamento. São Paulo: Ed. Loyola, 2000, p. 155.

${ }^{5}$ KAISER, W. C.; SILVA, M. Introdução à hermenêutica bíblica. São Paulo: Ed. Cultura Cristã, 2002, p. 29-30; EGGER, W. Metodologia do Novo Testamento. São Paulo: Edições Loyola, 2005, p. 207; FEE, G. D.; STUART, D. Entendes o que lês? Um guia para entender a Bíblia com o auxílio da exegese e da hermenêutica. São Paulo: Vida Nova, 2006, p. 265-267.

${ }^{6}$ EGGER, Metodologia do Novo Testamento, p. 201-206; SIMIAN-YOFRE, Metodologia do Antigo Testamento, p. 150-166; WEGNER, U. Exegese do Novo Testamento: manual de metodologia. São Paulo: Paulus, 1998, p. 310-316; SCHNELLE, U. Introdução à exegese do Novo Testamento. São Paulo: Edições Loyola, 2004, p. 151-181; etc.
} 
permite ir se ampliando ao longo das experiências históricas documentadas nos diversos tipos textuais em correspondência aos diversos contextos. Porém, esta ampliação não significa um crescimento linear de pensamento interno nos textos em sentido cronológico, pois estes comportam avanços também intercalados por retrocessos em determinadas situações históricas adiantes, contudo, o saldo do desenvolvimento da fé e da experiência refletida contribui para a possibilidade de abertura às novas leituras, saltos e ampliações (ainda que isto não ocorra univocamente) que exercem peso significativo para o todo da História-Salvífica, algo perceptível numa visão de conjunto das Escrituras.

Ora, se é verdade que a Bíblia registra a experiência religiosa de Israel e a maturação progressiva desta caminhada histórica (com altos e baixos), em cuja perspectiva se inclui o surgimento e desenvolvimento do cristianismo primitivo como parte desta história, segue-se daí que se quisermos apreender um tema bíblico no seu sentido verdadeiro, devemos segui-lo nas suas evoluções e apreendê-lo no seu conjunto, conforme propugnou John Mckenzie ${ }^{7}$. Portanto, na própria natureza do MHC existe todo um potencial para que seja captado o núcleo permanente (e, portanto, "normativo") nas suas "configurações mutáveis, vinculando o núcleo à mentalidade e à cultura das várias épocas", tornando possível trazer o profundo significado extraído para falar vivamente ao ouvinte de hoje. Se isto em determinadas situações não vem acontecendo, então pode estar muito mais relacionado às condições, competência, perspectiva ou pressupostos do sujeito que usa o método do que à qualidade científica do método em si e da respectiva melhoria contínua de seus objetivos. E sim, esta última premissa abrange todo e qualquer método de análise textual, não somente o MHC.

\section{A confluência da responsabilidade prática do biblista}

Entretanto, de início e ao longo da experiência o exegeta depreende nitidamente as limitações de cada método e também das abordagens adotadas. É justamente neste limite que surge o impulso de avançar e amadurecer nas problemáticas do texto e nas perspectivas de leitura, o que correspondentemente torna o aperfeiçoamento científico cada vez mais criterioso. Contudo, se deve ter o cuidado para não transformar seu trabalho em assunto de erutidos

\footnotetext{
${ }^{7}$ MCKENZIE, J. Dicionário Bíblico. São Paulo: Paulus, 2005, p. VII.

${ }^{8}$ MCKENZIE, Dicionário Bíblico, p. VII-VIII.
} 
para erutidos, ou como disse Uwe Wegner, "de letrados para letrados", e com isto, ao mesmo tempo que identifica criteriosamente o rosto e fisionomia sui generis do texto, se deixar cair no logro de perder a sensibilidade do interfaceamento deste "rosto" para com o leitor vigente que dialoga e faz uso do texto bíblico. Configura-se assim, que o maior desafio no aperfeiçoamento da ciência bíblica é fazer com que o significado profundo dos temas bíblicos, devidamente depreendido a partir da globalidade da História-salvífica, seja contextualizado para o momento contemporâneo sem com isto trair o propósito do texto em sua concepção e desenvolvimento, sem desviá-lo de seu sentido literal e ao mesmo tempo sem precisar ser literalista, oferecendo subsídios para uma leitura popular da Bíblia. Esta preocupação tem sua pertinência quando a história nos mostra que determinadas interpretações bíblicas contribuíram para fundamentar ou fomentar diversas posturas equivocadas como, por exemplo, a política africana do Apartheid, a escravidão, atitudes reacionárias do fundamentalismo religioso, a intolerância sexual, etc. Estes exemplos são extremos, mas há aqueles sutis que interferem na vida cotidiana, que privam o cultivo de relações saudáveis, ou impedem um tratamento médico, etc, devido determinadas interpretações as mais das vezes engolfadas pela precedência de um sentimento religioso. Não há como o exegeta se manter indiferente diante das questões contextuais que interpelam o texto bíblico e que o usam deliberadamente. Assim, pergunto, o que seria para a ciência bíblica borrar a linha tênue que separa o "dever" do biblista do "dever" do teólogo? Entre o "dever exegético" e o "dever pastoral" no tratamento do texto? E, ao mesmo tempo, desenvolver parâmetros para evitar o perigo de "obrigar" a Bíblia a falar apenas o que nos agrada e, por outro, evitar o erro de absolutizar a leitura ao "pé da letra", ou até manipuladora e "fora de lugar" que incentiva comportamentos nocivos conforme demonstrados na história? Nisto está a sina do exegeta, ao mesmo tempo em que borra linhas "limítrofes", acaba criando outras de outro tipo. Tentar escapar disto não seria falta de coragem nossa? Já que nossa responsabilidade é lidar com o texto que comporta inerentemente todas estas instâncias?

Somos levados a concordar plenamente com Alonso Schökel ${ }^{10}$ quando diz que os homens nos pedem pão e "lhes oferecemos um punhado de hipóteses sobre um versículo do capítulo 6 de João", nos interrogam acerca de Deus,

\footnotetext{
${ }^{9}$ WEGNER, Exegese do Novo Testamento, p. 13.

${ }^{10}$ MARTINEZ, J. M. Hermenêutica Bíblica (como interpretar las Sagradas Escrituras). Barcelona: Clie, 1984, p. 54.
} 
e "Ihes oferecemos três teorias sobre o gênero literário de um Salmo", as pessoas têm sede de justiça e "colocamos a sua frente uma inquirição etimológica sobre a raiz sedaqah...”. E, embora as definições em si nada estabeleçam, sua cuidadosa construção pode contribuir na orientação ou reorientação útil de pensamento para desenvolvimento de uma linha de pesquisa ${ }^{11}$, então, talvez devêssemos considerar o fato de que todo o nosso labor exegético estará incompleto enquanto não revisarmos a noção de "exegese", para além da investigação de "encontrar o sentido literal do texto em seu contexto", visto que, parafraseando Zimmermann, a ciência bíblica tem a "incumbência de conduzir a um conhecimento mais profundo da palavra de Deus como se apresenta na figura histórica do Novo Testamento, de apreender o seu conteúdo teológico e de conferir à sua mensagem voz compreensível para o homem de hoje"12. E ainda, como Wegner ressaltou, quanto mais o exegeta comungar, compartilhar e participar das experiências de fé e das correspondentes interpretações que estas experiências imprimem no texto e na vida dos fiéis, mais habilitado ele estará no exercício de suas interpretações e estará "mais sensível aos clamores, às perguntas e necessidades concretas das comunidades eclesiais"13.

\section{A construção de "pontes" no âmbito das dificuldades interpretativas}

No entanto, sabemos que a dificuldade de interpretação da Bíblia não é uma novidade moderna, e talvez as questões, por mais forte que se apresentem, como a distância temporal, geográfica, cultural, etc, não são os únicos fatores de dificuldade, visto que pessoas que compartilhavam a mesma época, local e cultura dos produtores bíblicos também tiveram dificuldades para compreender as Sagradas Escrituras, como explicitado na $2^{\text {a }}$ epístola de Pedro a respeito dos escritos de Paulo (2 Pd 3,16). Não só com Paulo, mas na compreensão de significado do que o próprio Jesus queria esclarecer sobre determinadas verdades profundas para além de uma interpretação superficial, por isso, "ouvistes o que foi dito aos antigos... eu, porém, vos digo...". Contudo, seus próprios conterrâneos ainda não o podiam "suportar" (Jo 16,12). Isto pontua que estamos num nível de dificuldade maior do que àquelas já existentes da época, por acrescentar-nos o fato de que não tivemos o privilégio de estar lá (no mesmo "espaço-tempo"), porém, como se pode constatar, esta

\footnotetext{
${ }^{11}$ GEERTZ, C. A interpretação das culturas. São Paulo: LTC, 1989, p. 67.

${ }^{12}$ ZIMMERMANN, H. Metodologia del Novo Testamento. Torino: 1971, introdução.

${ }^{13}$ WEGNER, Exegese do Novo Testamento, p. 13.
} 
dimensão cultural não seria ainda per si uma solução efetiva. Deste modo, no comportamento do mestre Jesus temos algo extremamente significativo sobre a atividade de releitura das Escrituras Sagradas. Mais do que com palavras, ele fez da própria vida uma interpretação viva do texto, e mostrou-nos de uma vez por todas o interesse no sentido mais profundo das Escrituras para além da superfície textual. E talvez, seja aí que reside a questão crucial do problema do significado: o texto é meio, instrumento, ferramenta e não o fim em si mesmo. Para a comunidade de fé a questão é crucial porque o antigo e canônico texto sagrado é tido como fonte de orientação para a vida e assume um caráter normativo, de cuja interpretação criteriosa, portanto, não se pode abrir mão, principalmente porque envolve esta questão mediadora e não absoluta da textualidade em si. Esta premissa, por mais simples que pareça, é um forte ponto crítico no modo de se relacionar com a Bíblia, o Livro por excelência, que é regra de fé e prática.

Assim sendo, as Sagradas Escrituras testemunham constantemente que a "Revelação de Deus se realiza através de formas, experiências e expressões religiosas do ambiente" ${ }^{14}$. Isso porque a palavra divina se manifesta na história, através do condicionamento sociocultural do ser humano com quem ela entra em interlocução. Mas a profundidade do discurso divino não se verifica simplesmente por releituras do que foi dito antes, e sim por releituras exigidas por novas situações, por eventos contemporâneos que provocaram novos questionamentos e pediam uma atualização da experiência religiosa sincera e fundamental. $\mathrm{O}$ alcance da mensagem essencial se realiza em função à fidelidade ao "hoje", à história, ao momento presente do leitor. Por estas razões é necessário um método que possibilite apreender e distinguir a essência da mensagem divina, também considerada "lógica de fundo", que emerge sempre mais do texto, dos recursos provisórios, das formações culturais do ambiente, formações superadas que vão ficando sempre mais à margem, abrindo espaço para ampliações, permitindo que a revelação da palavra viva seja atualizada em qualquer universo cultural. O escopo do biblista, portanto, não é o de substituir-se ao texto, de modo algum, mas unicamente o de permitir que o texto fale por si só, e assim, fazer falar o texto aos seus leitores contemporâneos. Certamente, isso constitui-se numa via de mão dupla: o texto só pode falar a quem está disposto a ser interpretado, a rever sua própria situação, transformar sua realidade e ir em direção a Deus e ao próximo, nisso reside a força de provocação do texto e o efeito desejável de sua validez.

${ }^{14}$ MCKENZIE, Dicionário Bíblico, p. IX. 
A aparente necessidade deste artigo seria propor uma pequena contribuição prática, contudo, mais que isto, este tem o pretexto de recapitular determinadas noções orientadoras na verdadeira finalidade de por o tema em debate e, assim, reavivar a necessidade de construirmos continuamente as "pontes" entre o passado e o presente, entre a profundidade tematizada no texto e a realidade vivencial, resgatando o significado essencial com o fim de ajudar a tarefa exegética na atualização da mensagem que continua ainda hoje a interpelar os seus ouvintes na sublime proposta de engajá-los cada vez mais no desenvolvimento salutar de nossa humanidade.

\section{Noções norteadoras de atualização textual constituídas em 7 princípios:}

Resumidamente, destacamos as orientações para uma devida contextualização do texto bíblico: $1^{\circ}$ ) Um texto não pode ter um significado hoje diferente do que foi para os leitores originais; $2^{\circ}$ ) Apreensão interpretativa através da comparabilidade textual; $3^{\circ}$ ) Diferenciar entre "forma" e "essência" preservando com isso a integração das Escrituras; $4^{\circ}$ ) Diferenciar entre valores temporários e valores constantes; $5^{\circ}$ ) Verificar a possibilidade de existirem circunstâncias comparáveis ou analogia da experiência; $6^{\circ}$ ) A lição profunda (núcleo permanente ou lição constante) tem capacidade de inculturação; $7^{\circ}$ ) Toda interpretação normativa deve visar a plenitude do desenvolvimento engajado de nossa humanização, do valor e da dignidade da pessoa humana.

Vejamos em seguida uma breve explicação de cada um destes princípios e como os mesmos contribuem para o esclarecimento da conclusão final.

$1^{\circ}$ Princípio - Um texto não pode ter um significado hoje diferente do que foi para os leitores originais.

O significado verdadeiro do texto é aquele (dado por Deus e mediado pelo escritor) pretendido que significasse no período do contexto bíblico. Este é o primeiro princípio ressaltado tanto por Gordon Fee e Douglas Stuart, no manual "Entendes o que lês" 15 , como também é o primeiro dentre os seis princípios de J. M. Matínez em seu manual de hermenêutica ${ }^{16}$. Depreendemos,

\footnotetext{
${ }^{15}$ FEE; STUART, Entendes o que lês, p. 48.

${ }^{16}$ MARTINEZ, Hermenêutica Bíblica (como interpretar las Sagradas Escrituras), p. 54.
} 
portanto, que o tema teológico central do texto está coligado a este princípio que não pode ser negligenciado. No decorrer das últimas décadas tem ocorrido um crescente interesse pela abordagem da Bíblia como literatura ${ }^{17}$, razão pela qual se torna necessário situá-la no universo de seu tempo e dar-lhe o tratamento "literário" a que tem direito ${ }^{18}$. Aliás, o estudo literário ${ }^{19}$ deve preceder qualquer atribuição de valor ao texto, pois, como disseram Alter e Kermode, "a menos que tenhamos um entendimento claro do que o texto está dizendo, ele não terá muito valor sob outros aspectos" ${ }^{20}$. Sendo a literatura uma linguagem complexa ${ }^{21}$ e não obstante distinta, a análise literária pode nos orientar no acesso a uma realidade do passado ${ }^{22}$, quanto às operações da linguagem no texto e, portanto, na eficiência da comunicação de sua mensagem no condicionamento de seu tempo e lugar ${ }^{23}$.

\section{$2^{\circ}$ Princípio - Apreensão interpretativa através da comparabilidade textual.}

Importante comparar o significado apreendido do texto lido com o sentido que aparece em outro(s) texto(s) do próprio livro, depois nos livros de mesma tradição ou bloco literário congênere (ex.: evangelhos, livros sapienciais, epístolas do mesmo autor, blocos proféticos, etc.), depois no restante de livros das Escrituras. Este comparativo pode ser de grande auxílio para a compreensão de passagens obscuras. Assim, as passagens mais difíceis podem ser esclarecidas por outras de mais fácil entendimento, ou através da temática tratada no contexto, ou através do objetivo global do livro, ou de outros textos escritos pelo mesmo autor, etc. Estabelecer esta correlação textual ou intertextual é deveras esclarecedor.

Esta validação numa primeira instância prioriza a totalidade dos livros canônicos. Contudo, podem ser admitidos textos extra-bíblicos dentro do período bíblico para ajudar a compreender o uso na época de termos, locuções e imagens que aparecem nas Escrituras. Mas é válido dizer que a comparação

\footnotetext{
${ }^{17}$ ALTER, R. Em espelho crítico. São Paulo: Perspectiva, 1998, pp. 16-17.

${ }^{18}$ Dr. Johan Konings apud BERGER, K. As formas literárias do Novo Testamento. São Paulo: Edições Loyola, 1998, p. 9.

${ }^{19}$ FERREIRA, J. C. L. Estudos literários aplicados à Bíblia. Disponível em < HTTP://www.revistatheos. com.br /artigos\% 20anteriores /Artigo_03_02.pdf>. Acesso em 03 janeiro 2011, pp. 2-3.

${ }^{20}$ ALTER, R.; KERMODE, F. (Eds.). Guia Literário da Bíblia. São Paulo: Editora Unesp, 1997, p. 13.

${ }^{21}$ ALTER; KERMODE, Guia literário da Bíblia, p. 15.

${ }^{22}$ SAUSSURE, F. Curso de linguística geral. São Paulo: Cultrix, 2012, p. 54.

${ }^{23}$ PONTIFÍCIA COMISSÃO BÍBLICA, A Interpretação da Bíblia na Igreja, pp. 41-45.
} 
com um material extra-bíblico não pode contradizer os ensinos fundamentais que aparecem na História-salvífica na globalidade das Sagradas Escrituras.

A Escritura no todo de seu conjunto nos ajuda no exercício interpretativo de qualquer texto bíblico em seu respectivo contexto ${ }^{24}$. Contudo, os próprios hagiógrafos usaram material extra-bíblico como recurso de comunicação. Os exemplos abaixo nos ajudam a compreender a importância inerente de estabelecer estratégias de comunicação no processo de interlocução (seja para efeito de analogias, apologias, associações, refutações, etc.). Os autores sagrados souberam retrabalhar as suas fontes, em meio a vicissitudes de suas experiências, repensá-las em função das tradições específicas do Povo de Deus, enfatizando a caminhada de fé. Veja algumas amostras: Judas 6-9 cita os apócrifos 1 Henoc e Assunção de Moisés; Paulo e Mateus fazem alusões ao Testamento dos Doze Patriarcas; Mateus e Marcos citam os Salmos de Salomão; No discurso de Paulo no areópago em Atenas são mencionados trechos de filósofos gregos; O relato sacerdotal da criação (Gn 1.1-2.4a) detém pontos de contato com a cosmogonia babilonica do "Enuma Elish"; O texto de Zacarias utiliza o mito de Adad-Rimmôn assimilado pela cultura cananéia como o deus Baal traspassado por Mot para retratar o herói davidida com quem Deus se identifica; etc.

Entretanto, não se trata de absorver este material "de fora" indiscriminadamente. A comparação demonstra a finalidade mediadora que os hagiógrafos adotaram, aproveitando o que foi útil para estabelecer pontes de entendimento. Mesmo os livros do Primeiro Testamento, admitidos como canônicos, precisam ser lidos com devido critério e maturação teológioca (quem hoje sairá para "exterminar mulheres e crianças"? Ou submeter um suspeito de adultério ao teste mágico do ordálio bíblico? etc.). Os próximos pontos têm a função de prestar auxílio na construção deste discernimento.

$3^{\circ}$ Princípio - Diferenciar entre "formas" e "essência" preservando com isso a integração das Escrituras.

A essência é a mensagem/sentido profundo dentro do texto, a realidade que o texto quer por em pauta. Esta mensagem pode ser articulada através de várias formas e modos de falar. Os escritores bíblicos usaram gêneros literários, tradições, figuras de linguagem, linguagem mitológica, ditos popu-

${ }^{24}$ A CONFISSÃO DE FÉ DE WESTMINSTER. São Paulo: Editora Cultura Cristã, 2003, p. 25. 
lares, etc., apenas como veículos para transportar o âmago do ensino bíblico. A mensagem essencial entretece os fios-condutores entre os textos, nesta essência está a lição profunda e a integração das Escrituras. Por exemplo: os dois relatos distintos da criação (Tabela 1):

\begin{tabular}{|c|c|}
\hline Narrativa Não-Sacerdotal (Gn 2,4b-25) & Documento Sacerdotal (Gn 1,1-2.4a) \\
\hline $\begin{array}{l}\text { - Usa o nome divino YHWH Elohim o } \\
\text { tempo todo; A criação é da terra e céu, } \\
\text { ocorre em } 1 \text { dia (2.4b). } \\
\text { - Sequência criacional: 1) o homem; 2) } \\
\text { os vegetais; } 3 \text { ) os animais e aves; 4) a } \\
\text { mulher. } \\
\text { - Para o ato criador usa a linguagem do } \\
\text { ambiente camponês: Deus "moldou", } \\
\text { "modelou" como artesão/oleiro } \\
(2,7.19 .22) \text {, jardineiro }(2,8) \text {, etc. }\end{array}$ & $\begin{array}{l}\text { - Usa somente o nome divino Elohim; A } \\
\text { criação é do céu e da terra, ocorre em } \\
6 \text { dias; } \\
\text { - Sequência criacional: 1) a luz; 2) } \\
\text { o firmamento; 3) a vegetação; 4) os } \\
\text { luminares; 5) os seres aquáticos e aéreos; } \\
\text { 6) os animais terrestres e a humanidade. } \\
\text { - Para o ato criador usa a linguagem } \\
\text { do ambiente litúrgico: Ação repetitiva } \\
\text { ritualista: "faça-se", "assim se fez", "viu } \\
\text { que era bom", "Deus chamou", "fez-se } \\
\text { tarde e manhã". Terminologia cúltica: } \\
\text { "abençoou", etc. }\end{array}$ \\
\hline
\end{tabular}

Tabela 1 - Comparativo de diferenças entre os dois relatos da cosmogonia bíblica

Este exemplo clássico mostra que a verdade da Revelação não é literalísticamente o modo como fala, mas a lição apreendida. Por que a tradição judaica preservou estes dois relatos de características distintas na Escritura? Pelo fato de trazerem uma coesão de lição profunda permanente em ambas redações: Há um único Deus; Deus é pré-existente ao mundo; Deus cria o universo por Sua expressa vontade soberana (e não por batalhas divinas); Deus mantém o cosmos organizado; Os seres humanos recebem a especial atenção divina; O poder criador de Deus subverte o caos ("caos" tematizado num relato como o abismo primevo e no outro como terra desértica); $O$ poder criacional é um poder libertador do caos, que constrói a vida onde não haveria possibilidade de existir; etc. Porém, a abordagem fundamentalista insiste em que a inerrância das Escrituras está em cada detalhe do modo de falar, como se em tais detalhes existisse uma veracidade científica, histórica, biológica, etc. Mas isto não era o propósito pretendido pelos textos. A inerrância das Escrituras está em seu sentido mais profundo que aponta eficazmente para Deus e projeta o encontro do homem com Deus, encontro este 
capaz de transformar o ser humano. Os detalhes das formas de falar foram instrumentos correspondentes ao processo histórico-cultural da época. Hoje podemos utilizar os instrumentos culturais do ambiente contemporâneo na mesma finalidade de ilustrar e tornar acessível o âmago da lição bíblica. $\mathrm{O}$ espírito da mensagem não está restrito a um único veículo de comunicação.

As formas literárias exercem importante papel no discernimento da intencionalidade textual. A situação vivencial (sitz im leben) engendra o modo adequado de expressão. No século passado a ciência bíblica forneceu uma das maiores contribuições no que diz respeito ao progresso metodológico de análise e compreensão de texto da Antiguidade: a descoberta, análise e classificação dos gêneros literários ${ }^{25}$. O estudo das formas ajudou na análise dos tipos ou gêneros literários, recolhendo-os em grupos com estruturas análogas, determinando suas características e tentando apreender seu ambiente social e os campos de interação nos quais os tipos de textos se inscrevem. A pergunta pela intencionalidade do texto pode ser abordada em estreita conexão com o respectivo gênero literário. A partir disto se compreende qual tipo de projeto comunicativo ${ }^{26} \mathrm{e}$ modelo expressivo o autor empregou para impactar sua audiência (Tabela 2).

Muito do texto bíblico documenta um arco histórico de formação textual por releituras e reinterpretações de experiências (uma das razões de encontrarmos relatos replicados: Gn 15 e 17; Êx 3 e 6; etc). Na teoria literária ${ }^{27}$ da Antiguidade a comparação pela releitura ajudava o leitor a depreender o que precisava ser reforçado, adaptando o gênero, as formas, as palavras e linguagem figurada a um novo contexto, mas visando preservar o sentido mais profundo e os fios-condutores de um contexto para o outro. A compreensão era ampliada de acordo com a necessidade e condições das novas circunstâncias a fim de tornar o sentido plenamente audível (compreensível e significativo) no momento da redação. Ex.: As versões do decálogo ${ }^{28}$ (Êx 20,2-17 Dt 5,6-21), apesar das divergências no motivo da guarda do sábado, o sentido profundo do conjunto se manteve; leia ainda: Am 9,11-12 $\leftrightarrow$ At 15,16-17; Is $44,3 \leftrightarrow$ Jo 7,38; Jl 3,1-2 BJ (ou J1 2,28 Almeida) $\leftrightarrow$ At 2,17.

\footnotetext{
${ }^{25}$ LUÍS-SICRE, J. Profetismo em Israel: O profeta, os profetas, a mensagem. Petrópolis: Editora Vozes, 2002, p. 142-143.

${ }^{26}$ CONCÍlIO VATICANO II. Dei Verbum, cap. III, 12.

${ }^{27}$ OTTO, A lei de Moisés, p. 99-119.

${ }^{28}$ ARTOLA, A. M.; CARO, J. M. S. A Bíblia e a Palavra de Deus. São Paulo: Ed. Ave Maria, 2005, p. 233.
} 


\begin{tabular}{|c|c|c|}
\hline $\begin{array}{l}\text { Situações Vivenciais } \\
\text { Típicas (Sitz im Leben) }\end{array}$ & $\begin{array}{l}\text { Gêneros } \\
\text { Literários }\end{array}$ & Efeito prático desejado \\
\hline - Situação de vitória & - Hinos e cânticos & $\begin{array}{l}\text { - Levar a comunidade agradecer } \\
\text { e reconhecer um poder além de } \\
\text { si mesmos. }\end{array}$ \\
\hline $\begin{array}{l}\text { - Situação de derrota / } \\
\text { fracasso. }\end{array}$ & - Lamentações & $\begin{array}{l}\text { - Levar a refletir e rever as } \\
\text { atitudes. }\end{array}$ \\
\hline $\begin{array}{l}\text { - Quando a aristocracia } \\
\text { teme de ser solidária com } \\
\text { as classes pobres. }\end{array}$ & - Rîb & $\begin{array}{l}\text { - Realizar uma ação pastoral } \\
\text { capaz de acusar a consciência, } \\
\text { levar à solidariedade. }\end{array}$ \\
\hline $\begin{array}{l}\text { - Quando o líder e/ou a } \\
\text { comunidade se desviam } \\
\text { da prática da justiça }\end{array}$ & - Profecia & $\begin{array}{l}\text { - Re-alinhar a comunidade em } \\
\text { direção ao alvo da aliança e } \\
\text { assim impulsionar a construir } \\
\text { a história e o futuro. }\end{array}$ \\
\hline $\begin{array}{l}\text { - Situação de falta de } \\
\text { recursos. }\end{array}$ & $\begin{array}{l}\text { - Relatos de } \\
\text { milagres }\end{array}$ & $\begin{array}{l}\text { - Suscitar confiança, fazer } \\
\text { enxergar além do circunstancial, } \\
\text { Deus pode suprir de onde menos } \\
\text { se espera. }\end{array}$ \\
\hline $\begin{array}{l}\text { - Perseguição sob a } \\
\text { dominação estrangeira. }\end{array}$ & - Apocalíptico & $\begin{array}{l}\text { - Codificar uma mensagem } \\
\text { (para não ser interceptada) a } \\
\text { fim de suscitar esperança. }\end{array}$ \\
\hline
\end{tabular}

Tabela 2 - Exemplos da relação entre situação, gênero e efeito desejado

$4^{\circ}$ Princípio - Diferenciar entre valores temporários e valores constantes.

Valores Temporários (estão fixados em condições limitadas da cultura) são ensinos e observâncias em função da cultura, mas que ao longo da história bíblica foram descartados. Ex.: a prática da circuncisão, a lei do interdito (destruição total de cidades conquistadas), rituais sacrificais, a guarda do sábado, a divindade "habitar" no templo, a lei do talião, escravidão, etc.

Valores Constantes (estão fixados no fio condutor das Escrituras) - O "núcleo permanente" presente na globalidade da História-salvífica tem valor normativo, portanto, são diretrizes e determinações explícitas que reaparecem insistentemente nos períodos da história bíblica desde o antigo Israel às experiências históricas do cristianismo originário. Enquanto o $3^{\circ}$ princípio se atém ao nível literário, este $4^{\circ}$ princípio abrange todos os elementos normativos 
da cultura (conceitos, ética, diretivas, princípios, etc.). Ex.: Ensinos como a unicidade de Deus, Deus criador-libertador, os temas da justiça e do amor, da comunhão, da humildade, da dependência de Deus, da conversão de vida, o problema do pecado e do fechamento ao próximo, atender o chamado de Deus, compartilhar com o outro a experiência de Deus, sociedade-igualitária, etc.

\section{$5^{\circ}$ Princípio-Comparabilidade de circunstâncias ou possibilidade de analogia da experiência.}

Sempre quando compartilhamos circunstâncias (situações típicas de vida) com o âmbito do leitor originário, o âmago da Palavra de Deus dirigida para eles tem o mesmo sentido para nós, contudo isto implica na compreensão do que a Palavra de Deus queria dizer $\left(1^{\circ}\right.$ e $2^{\circ}$ princípios $)$ naquela circunstância, qual era a essência de sua mensagem ( $3^{\circ}$ princípio) e se esta aparece como um valor constante ( $4^{\circ}$ princípio). Assim sendo, não cabe aplicar automaticamente o texto sem ater à possibilidade de uma analogia da experiência e muito menos sem passar pelos critérios acima. Importante verificarmos que este procedimento ocorreu no interior da história da redação bíblica (Ex.: oráculos dirigidos ao Reino do Norte, que mais tarde foram atualizados ao Reino do Sul devido a situação análoga - Mq 1.2-7; Am 2.4-5; etc). Em certa medida aqui temos em pauta o conceito de conaturalidade. Comparar situações na História-Salvífica, ou passar por uma experiência semelhante do escritor ou do destinatário, como também comungar das experiências dos interlocutores para quem o hermeneuta está interpretando seu texto pode servir de forte auxílio na exposição do significado apreendido. A conaturalidade pode atingir estes níveis. Este princípio nos ajuda a fazer as perguntas certas ao texto: Qual é o propósito do texto (e do livro do texto) em relação ao seu respectivo contexto vivencial? Quais âmbitos da nossa experiência podem ser iluminados pela mensagem do livro? A situação que o leitor atual atravessa tem paralelos àquela (salvo as devidas proporções)?

$6^{\circ}$ Princípio - A lição profunda do texto (núcleo permanente ou lição constante) tem capacidade de inculturação.

A mensagem essencial da Palavra de Deus concedeu à Bíblia uma abertura universal que fez com que esta pudesse ser acolhida em qualquer cultura: 
1) Por isso, temos condições de oferecer reflexões e respostas às questões humanas que a cultura contemporânea interpela à inteligência e consciência cristã;

2) Jamais um ensino extraído das Escrituras para os dias de hoje deve incentivar atitudes etnocêntricas (não se trata de suplantar todas as outras culturas para impor uma suposta cultura "superior"), por isso, não se deve impor costumes, formas de se vestir, hábitos alimentares, etc. E jamais deve incentivar à hostilidade, ao ódio, à tortura, à violência ou à privação da liberdade;

3) A mensagem bíblica profunda é capaz de fecundar sistemas de valores ${ }^{29}$, promovendo o respeito ao próximo, o amor, a dignidade humana, a maturidade por meio da livre decisão pessoal, a coragem de lutar pelo valor da vida, da justiça, da igualdade, da misericórdia e do perdão. Esses são valores que estão no fio condutor salvífico, que são capazes de produzir frutos transformadores para a nossa sociedade e de gerações futuras;

4) O projeto salvífico de Deus é um projeto de humanização, para isto se deu a encarnação do Cristo e para isto converge toda a Escritura. Este ponto não só garante como põe em evidência a unidade das Escrituras em sua diversificação textual.

$7^{\circ}$ Princípio - Toda interpretação normativa deve visar a plenitude do desenvolvimento engajado de nossa humanização, do valor e da dignidade da pessoa humana.

Os autores bíblicos não hesitaram em haurir, direta ou indiretamente, das tradições e materiais do Antigo Oriente Próximo. As descobertas arqueológicas de aproximadamente de um século para cá mostram que existem muitos pontos em comum entre as páginas das Sagradas Escrituras e determinados textos de Mari, Nuzi, Ebla, Ugarit, etc. Mas, a pesquisa científica revelou igualmente que os escritores bíblicos não foram imitadores servis. Portanto, longe de ser mera cópia, modelos vizinhos foram adaptados comportando o conteúdo original e próprio da experiência do povo de Deus com Deus. "Israel foi um povo forjado no fogo da História. Assimilando com força singular toda a espécie de influxos, jamais perdeu, porém, seus traços essenciais". ${ }^{30}$

\footnotetext{
${ }^{29}$ PONTIFÍCIA COMISSÃO BÍBLICA, A interpretação da Bíblia na Igreja, p. 145.

${ }^{30}$ LÍNDEZ, J. V. Sabedoria e sábios em Israel. São Paulo: Ed. Loyola, 1999, p. 18.
} 
Os textos das Sagradas Escrituras objetivaram tratar temas relacionados a uma experiência viva de Deus. O desenvolvimento da literatura bíblica se serviu de processos históricos, ideológicos, semiológicos, como os de preservação da memória, legitimações institucionais, tensões de escolas, reconstrução da identidade nacional e comunitária, etc., e ao mesmo tempo extrapolou tudo isto. A teologia judaica e cristã irá reler as antigas tradições das Sagradas Escrituras para aprender o mistério do propósito da origem do mundo e o sentido de seu destino, bem como a ampliação da ação salvífica de Deus no universo. O fato de os produtores bíblicos terem interagido com os processos de suas épocas e de terem usado todo um acervo intercultural que continha conhecimento tácito próprio do ambiente religioso mediterrâneo-palestino, prova que a mensagem bíblica perpassou por uma constante interlocução cultural e, por isso, é capaz de ultrapassar seu ambiente de origem e, assim, de inculturar em abrangência universal os valores que estão a serviço salvífico da humanidade. Assim, não só a dimensão pessoal e individual deve ser considerada na leitura "atualizada", pois esta deve confluir e direcionar para a dimensão comunitária, eclesial, social, e ecológica, enfim, ao bem comum e dialogal.

Para o cristianismo o parâmetro de plenitude está na experiência viva de Jesus de Nazaré, que se pôs definitivamente a servir ao próximo, como pura expressão do que é a vida de Deus, vida digna esta que corrige o egoísmo, o fechamento e a ganância, atitudes resultantes do mau uso das faculdades humanas e da compreensão e disposição obliteradas. O encontro com Deus leva o ser humano a sair de si mesmo e se por em direção a um projeto mais significativo e abrangente que nos conduz ao crescimento. $\mathrm{O} 7^{\circ}$ princípio evidencia, portanto, a dimensão teológica que pesa para o resultado desejado. Esta dimensão é qualificadora e só pode ser captada à luz da fé, para a qual todos os elementos culturais anteriores (experiências, histórias, comparativos, ethos, tradições, linguagens, reflexões, etc.) encontram completude e realização. Este último princípio aglutina todos os princípios anteriores.

\section{Conclusão}

O ser humano é histórico e relacional. Deus se revelava no seio da história, Israel percebe isso desde cedo e vê que as descrições não carregavam apenas o sentido que podia se receber, mas apontava para além de si mesmo. Para Israel e para nós (que temos fé), nada acontece por um acaso. Tudo o que ocorre tem um sentido radical que atravessa tudo. É o próprio Deus que deixa 
seus sinais e pegadas na história. Para os cristãos o evento Jesus Cristo traz a chave-interpretativa para explicar tudo que vem antes dele e depois dele. Este evento não é anacrônico, mas catacrônico ${ }^{31}$. Nas Escrituras temos uma meta de plenitude de vida espelhada no Cristo confessional do cristianismo originário, mas este não pertence exclusivamente aos cristãos, antes de tudo seu legado é um legítimo patrimônio da humanidade, do qual a comunidade cristã nasceu e para o qual se abre e direciona sua vida.

Portanto, os temas fios-condutores das Escrituras desembocam na plenitude da experiência totalizadora em que o quadro sociocultural permitiu que esta fosse tratada e tematizada parcialmente no texto, mas detém toda uma carga jubjacente de formação histórica que, na sua apreensão global, funciona para apontar na direção da verdadeira realidade que é a experiência viva de Deus. A Escritura nasceu desta fé, existe para gerar fé e, por isso, precisa de uma exegese que seja desenvolvida dentro da moldura da fé $\mathrm{e}^{32} \mathrm{em}$ todas as etapas e não somente num momento final. Para que um método de compreensão possa captar o Espírito do texto, o mesmo precisa ser orientado e desenvolvido dentro do mesmo Espírito do texto.

Assim, o expediente norteador que este artigo chama de "Os 07 princípios de atualização" não é uma substituição aos métodos exegéticos clássicos, antes os pressupõe, quaisquer que sejam. Por conseguinte, apesar de sua função em auxiliar na revisão de pontos sobre a atualização do sentido, este aprecia o cerne teológico que também precisa ser valorizado em todas as etapas da exegese. Em uma metáfora, o método bíblico é parecido com uma receita culinária, isto é, além de possuir o passo-a-passo de instruções técnicas, também indica seus ingredientes: os conteúdos da Revelação, apreendidos pela fé, atestados nas tradições bíblicas e na experiência de um vívido, salutar e regenerador encontro com Deus. Porém, o que foi dito acima não se trata de predispor ao exercício metódico uma determinada tendência teológica, antes, o que queremos dizer é que o texto reflete ou está dentro de um escopo teológico, cujo dado profundo, conteúdo e significado precisa ser colocado em evidência e respeitado, visto a natureza de fé e razão de existência das Sagradas Escrituras.

\footnotetext{
${ }^{31}$ Não se trata de colocar Jesus em cada texto das Escrituras, antes, de identificar os valores essenciais e nucleares presentes no todo das Escrituras que Jesus ressaltou em sua própria experiência. Isto excede se deter somente nas passagens específicas messiânicas. BERKOF, L. Princípios de interpretação bíblica. São Paulo: Editora Cultura Cristã, 2004, p. 23.

${ }^{32}$ LIMA, M. de L. C. Fundamentalismo: Escritura e Teologia entre fé e razão. Atualidade Teológica, 33 (2009), p. 358.
} 
Por fim, nas Sagradas Escrituras não há formulações sistematizadas de cada doutrina bíblica. Elas se apresentam aqui e acolá no nível de confissões de fé, homologias, doxologias, etc, como fórmulas breves que traduzem o essencial que animava a comunidade do Povo de Deus ${ }^{33}$. Contudo, os escritores neotestamentários interpretaram todo o acervo do Primeito Testamento e apreenderam seu conteúdo à luz dos gestos e ensinos de Jesus, atestando a plenitude da experiência do Cristo. Isto é central na interpretação cristã. Entendemos que a comunicação divina é fazer com que os homens rompam a obstacularização de suas construções humanas para se relacionarem entre si na "imagem e semelhança divina" uns com os outros, este é o âmago do amor ágape. Nosso Mestre, o Senhor Jesus, compreendeu, interpretou e revelou em sua releitura da História-Salvífica os valores essenciais bíblicos, razão pela qual a expressão "exegésato" do evangelho joanino $(1,18)$ o reconhece como o pleno exegeta do Pai. Estes valores que ele "acolheu" em sua própria humanidade e nos externou sintetizam a vida de Deus Pai, e ele fez disto seu projeto de vida pessoal que deve ser seguido: "vem e segue-me". Ele é o exegeta bíblico por excelência.

Concluindo, a mensagem de Deus sempre será límpida, sempre estará a serviço da ampliação de nossa compreensão da vida, do propósito de nossa existência e da saúde de nossas relações em todas as suas dimensões, porque são estas relações que definem, em primeira e última instância, o que realmente somos. Uma leitura atualizada permite que não somente nós venhamos interpretar o texto, mas como disse Uwe Wegner, ela também faz com que o texto bíblico tanto nos interprete quanto também interprete nosso contexto, e reflita num espelho nossa realidade, a fim de enxergarmos nossos limites e desafios, nos interpelando a transcender e nos convidando a apreender o significado profundo da vida no encontro existencial que nos ajuda a ir para além de nós mesmos, em rumo à plenificação do todo. Uma leitura revigorante das Sagradas Escrituras que se preze nos ajudará a caminhar profundamente nesta compreensão.

\section{Referências Bibliográficas}

A CONFISSÃO DE FÉ DE WESTMINSTER. São Paulo: Editora Cultura Cristã, 2003.

AGUIRRE, R. Os milagres de Jesus: perspectivas metodológicas plurais. São Paulo: Edições Loyola, 2009.

${ }^{33}$ THEOBALD, C. A revelação. São Paulo: Ed. Loyola, 2006, p. 37. 
ALONSO-SCHÖKEL, L. Hermeneutica de la Palavra. Madrid: Cristandad, 1986.

ALTER, R. Em espelho crítico. São Paulo: Perspectiva, 1998.

ALTER, R.; KERMODE, F. (Eds.). Guia Literário da Bíblia. São Paulo: Editora Unesp, 1997.

ARTOLA, A. M.; CARO, J. M. S. A Bíblia e a Palavra de Deus. São Paulo: Ave Maria, 2005.

BERGER, K. As formas literárias do Novo Testamento. São Paulo: Edições Loyola, 1998.

BERKOF, L. Princípios de interpretação bíblica. São Paulo: Editora Cultura Cristã, 2004.

CONCÍLIO VATICANO II. Dei Verbum, cap. III, 12.

EGGER, W. Metodologia do Novo Testamento. São Paulo: Edições Loyola, 2005.

FEE, G. D.; STUART, D. Entendes o que lês? Um guia para entender a Bíblia com o auxílio da exegese e da hermenêutica. São Paulo: Vida Nova, 2006.

FERREIRA, J. C. L. Estudos literários aplicados à Bíblia. Disponível em <HTTP: //www.revistatheos.com.br /artigos\% 20anteriores / Artigo_03_02.pdf $>$. Acesso em 03 janeiro 2011.

GEERTZ, C. A interpretação das culturas. São Paulo: LTC, 1989.

KAISER, W. C.; SILVA, M. Introdução à hermenêutica bíblica. São Paulo: Cultura Cristã, 2002.

LIMA, M. de L. C. Fundamentalismo: Escritura e Teologia entre fé e razão. Atualidade Teológica, 33 (2009).

LÍNDEZ, J. V. Sabedoria e sábios em Israel. São Paulo: Ed. Loyola, 1999.

LUÍS-SICRE, J. Profetismo em Israel: O profeta, os profetas, a mensagem. Petrópolis: Vozes, 2002.

MARTINEZ, J. M. Hermenêutica Bíblica (como interpretar las Sagradas Escrituras). Barcelona: Clie, 1984.

MCKENZIE, J. Dicionário Bíblico. São Paulo: Paulus, 2005.

OTTO, E. A Lei de Moisés. São Paulo: Ed. Loyola, 2011. 
PONTIFÍCIA COMISSÃO BÍBLICA. A interpretação da Bíblia na Igreja. São Paulo: Paulinas, 1994.

SAUSSURE, F. Curso de linguística geral. São Paulo: Cultrix, 2012.

SCHNELLE, U. Introdução à exegese do Novo Testamento. São Paulo: Edições Loyola, 2004.

SIMIAN-YOFRE, Horácio (coord.). Metodologia do Antigo Testamento. São Paulo: Ed. Loyola, 2000.

THEOBALD, C. A revelação. São Paulo: Ed. Loyola, 2006.

WEGNER, U. Exegese do Novo Testamento: manual de metodologia. São Paulo: Paulus, 1998.

ZIMMERMANN, H. Metodologia del Novo Testamento. Torino: 1971.

Vitor de Oliveira Abreu

Mestre em Teologia pela PUC-Rio Professor do CEFORTE - Centro de Formação Teológica- RJ Professor do IBE - Instituto Bíblico Ebenézer - RJ

Rio de Janeiro/RJ - Brasil

E-mail: consultor.vitor@gmail.com

Recebido em: 01/06/13

Aprovado em: 08/10/13 